\title{
Competence Approach as Factor of Higher School Students' Professional Mobility Development
}

\author{
Marina B. Balikaeva* \\ Department of Cross-cultural Communication, Tyumen Industrial University, Lunacharskogo 2, 625002 Tyumen, Russia
}

\begin{abstract}
The article studies the concept of "professional mobility" based on the philosophical, psychopedagogical and sociological literature analysis. It discusses the competence approach specificity as a factor of the students' professional mobility development process. The research reveals the criterionevaluation complex components for checking the pedagogical conditions effectiveness and providing the students' professional mobility development process by means of the competence approach implementation. It considers the pedagogical conditions complex for the students' professional mobility development by means of the competence approach implementation and shows its practical implementation. The pedagogical experiment results of theoretical provisions are presented. This article will be very useful for theoretical pedagogics.
\end{abstract}

\section{Introduction}

The higher education content modernization in the information society conditions depends on many factors and conditions for identifying reserve opportunities of the future specialists' study quality. The appearance of reserve opportunities is largely due to the competence approach implementation. The competence approach allows us to focus on the education results - general cultural, general professional skills and competencies. Students' orientation has become the professional mobility development by means of the competence approach implementation especially relevant because the Russian system of higher education must comply with European standards in the context of the Bologna process. According to the modern higher education tasks, the students' professional mobility development includes a sufficient level of general cultural, general professional skills and competencies.

\section{Discussion}

The problem analysis has made it possible to reveal the researchers' approaches to the concept "mobility" in the scientific literature. The category "mobility" has been studied in pedagogics relatively recently, but it is widely used in a number of scientific disciplines: psychology; educational philosophy; economy; vocational education and training [1] and others. The ideas for new forms of education are oriented towards the skill development of creativity and innovation in engineering activity. Many philosophers, sociologists, psychologists and educators expressed them long before the appearance of "professional mobility" practice.

On the basis of a philosophical approach to the professional mobility problem (Emile Durkheim, Max Weber and others) we defined that an important role in the mobility understanding also plays the dialectical law of unity and struggle of opposite. The different approaches presence proves its multifactorial, versatility, causes a scientists' interest on the psycho-pedagogical, educational and social aspects of the phenomenon.

In my opinion, the professional mobility as a complex integrative phenomenon includes the sociological, pedagogical and psychological components. Some authors give the common definitions of this phenomenon [1-3 and etc.] and consider sociological aspects of professional mobility.

The views of philosophers, educators and psychologists on the professional mobility problem in science helped me define the conceptualization of "professional mobility". I consider the professional mobility as an integrative engineer quality in the production conditions, the basic components are professional culture (key competencies and qualifications) and professional competence (high intelligence, creative skills, professionalism). It reflects in the ability to move horizontally and vertically on the social professional structure of society and to change a social, economic and professional (including status) position and captures the motivational, cognitive, competence-based, operative, active components, reflecting a certain level of general cultural, general professional skills and competencies $[4,5]$.

* Corresponding author: marinabalikaeva@ list.ru 


\section{Problem statement}

We can predict that the educational process builds on the base of the competence approach and aims at the formation of various students' competencies. During the analysis of the literature [1;3 and etc.], the developed professional mobility is the result of both the process of professional mobility development and the formation of general cultural, general professional skills and competencies. Thus, the students' professional mobility effective development process is possible through the formation of general cultural, general professional skills and competencies and can be considered as a parallel, mutually influencing process.

The professional mobility development occurs by means of the general cultural, general professional skills and competencies formation. The professional mobility development of by means of the general cultural, general professional skills and competencies formation ultimately leads to self-processes and represents a selfcontained cycle.

The professional mobility development process by means of the competence approach implementation is the students' experience in higher school. Therefore, the interactive ways of teaching in the classroom are pedagogically important as a subsequent discussion. You can see the students' experience during the discussion. This means that among the "competence" methods should include not only "activity" (for example, role-playing and business games, project method, training practice, qualification works), but also interactive learning methods, open discussions of new terms, subject positions.

Next we will introduce interactive ways of teaching.

Pedagogical games (business games, simulation games, operational games, role-playing games, didactic games) have clearly defined goals. In the process of the game, there is an intensive formation of all general educational skills.

Pedagogical games help the students define a goal and determine a situation, a problem. The students can find an optimal (most rational) solution and develop a program of activities or project of implementation solutions.

The researchers also call the following effective "competence" ways of learning. They are a critical thinking through reading and writing, a debate ("round table"), a case study method, a portfolio method, a project method.

The critical thinking method through reading and writing, an educational technology developed in foreign pedagogy are a system of methodical techniques designed for use in various subject areas, types and forms of work. Technology allows the students to achieve such educational results as general educational skills. They are an ability to work with sources of increasing information in different fields of knowledge, a correlation of the result with the goal and self-assessment, a creation of original ideas, an organization and participation in joint creativity, a building arguments etc. The technology includes the basic methods of pedagogical activity, the principles of organizing training groups.
The debate as an educational technology is aimed at the achievement of the following general educational skills. They are a critical approach to information, a determination of the importance of information, reliability of the facts, drawing conclusions, determination of the logical, chronological facts sequence, interaction with other people, with objects of the surrounding world and its information flows, etc.

The case study method helps to solve problems with the analysis of the specific situations taken from practice. The case study method is a good tool for the educational skills formation.

The portfolio method is a form of working with the products of students' independent activity for development of reflection and their awareness of their own subjective position. The portfolio method is a way of key competencies formation.

As a rule, the portfolio is a storage folder, in which various materials are placed. The classical portfolio should consist of 4 sections: "Portrait", "Collector", "Working Materials" and "Achievements".

The project method is the most obvious way of students' educational skills formation. In the course of solving the problem, students should be able to analyze, diagnose the problem, formulate goals, perceive and evaluate information, plan and implement their actions to achieve the project goals.

The "competence" methods listed above reveal the possibility of an organic combination of professional and educational knowledge and skills.

As criteria for the students' professional mobility development are identified (social, educational and personal), there are three levels of the professional mobility development (reproducing, interpreting and creative).

The indicators characterize the levels of students' professional mobility development by means of the competence approach. They are general cultural, general professional skills and competencies.

There are the diagnostic techniques to measure each indicator: knowledge in the organization field is the author's didactic test [6]; general educational skills are the author's test of unfinished sentences [7]; general cultural, general professional skills and competencies are expert evaluation $[2: 8 ; 9]$, teachers' questionnaires on the analysis of creative works and the students' answers and the professional mobility development program for students.

The pedagogical conditions for the professional mobility development are the creation of heuristic situations for cognitive independence of students, the organization of technological support for productive learning (problematic, productive methods and methods of self-control, with mastering the methods of independent recognition activity), the process activation for interactive and traditional active learning methods.

The experiment had three stages and was carried out on the basis of Tyumen State University of Architecture and Civil Engineering. The 389 first-year students from universities in Tyumen and nearby regions (Tobolsk, Khanty-Mansiysk, Kurgan, etc.) took part in the 
preliminary diagnostic experiment. The 103 first and second year students took part in the training experiment.

Taking into account the requirements of the competence approach implementation, a pedagogical conditions complex promotes the general cultural, general professional skills and competencies, which directly affect the students' professional mobility development. The results of the diagnostic stage confirmed our point of view. In the experiment, we used the same indicators for the first and second year students. After that, we summarized the measuring results of the students' professional mobility development level.

In order to obtain the objective information in analyzing the results, I used the formula (1):

$$
\bar{x}=\frac{1}{n} \sum_{i=1}^{n} x_{i}
$$

$\mathrm{n}$ - the number of respondents;

$x_{i}$ - the level of the higher school students' professional mobility development;

The average index was calculated by the formula (2):

$$
\mathrm{AI}=\frac{a \div 2 b \div 3 c}{100}
$$

At the beginning of the experiment, the reproducing level of students' professional mobility development had a significant number of students $(56.4 \%)$, while the interpretive level according to the main criterion characterized only $22.7 \%$ of the students and the creative level had $22.7 \%$. At the end of the experiment, the number of students in the experimental groups of the interpretive level had $39.7 \%$. At the same time, the creative level of the students' professional mobility development reached $29.03 \%$, and at the reproductive level, there were $31.2 \%$. It proves the effectiveness of the selected conditions for the students' professional mobility development.

\section{Research objective}

The research objective is to develop, to substantiate theoretically and to test experimentally a pedagogical conditions complex for the higher school students' professional mobility effective development by means of the competence approach implementation.

In order to achieve this objective, it is necessary to resolve the following research tasks:

The determination of the content of the definition "students' professional mobility based on the psychological and educational literature analysis".

The experimental test of the pedagogical conditions complex aimed at the higher school students' professional mobility development by means of the competence approach implementation.

We can foresee that the research methodological basis for my analysis of the students' professional mobility development are a competence approach to the students' professional mobility development, a personality-oriented activity.

Theoretical method is an analysis of philosophical, psycho-pedagogical, social and pedagogical literature on the problem under study. The general empirical method is an included observation of the higher school students' professional mobility development process by means of the competence approach implementation, psychological and pedagogical testing, a survey, a study of students' independent cognitive activity results, an educational experiment, expert opinions, mathematical methods of data processing, questionnaires.

\section{Results}

We obtained the results during the experiment to determine the average index (AI), the absolute growth rate $(G)$, the efficiency coefficient of the experimental method determined by the method of N. N. Ryauzov. For all indicators, we have received the positive dynamics in the application of mathematical methods. We had the reliability of the experimental data by means of the Pearson criterion $\chi^{2}$ (the method of M.I. Grabar). We confirmed a positive dynamics in terms of indices $\mathrm{T}_{\text {obs. }}>\mathrm{T}_{\text {crit }}$. The final calculations corroborated our assumption that the implementation of the proposed pedagogical conditions complex promotes the achievement of the highest level of higher school students' professional mobility development.

\section{Conclusions}

The complex of the pedagogical conditions promotes the future engineers' professional mobility development process. Thus, the pedagogical experiment confirms and proves the effectiveness of the students' professional mobility development by means of the competence approach implementation.

In summary, the research tasks are solved, the aim is achieved.

\section{References}

1. M. Spector, M. D. Merrill, J. Elen, M. J. Bishop, Handbook of Research on Educational Communications and Technology (Spinger, 2014)

2. A. Abdullin, The pedagogical problems of a cognitive attitude person formation (2001)

3. Ly Thi Tran, K. Dempsey, Springer Publishing 25 (2017)

4. M. Balikaeva, Theoretical and Methodological Foundation for Students' Professional Mobility in Higher School Social and Cultural Environment (2017)

5. M. Balikaeva, Mod. Jour. of Lang. Tea.Meth., 7, 7078 (2017)

6. B.Bitinos, Pedag. 2, 10-15 (1993) 
7. E. Zeer The personally oriented technology of the specialist professional development (1999)

8. M. Grabar, The application of mathematical statistics in pedagogical research. Nonparametric methods (M.: Pedagogy, 1977)

9. N. Ryauzov, The statistics general theory (Statistika, 1971)

*Corresponding author: marinabalikaeva@list.ru 